\title{
Always Together: How Football Clubs Want Constant Connections with Fans
}

\author{
By Fernando Vannier Borges*
}

Football clubs represent communities; however, commercialisation and professionalization of the game pushed away these traditional links. At the present, clubs are able to control the flux of communication, employing media consultants, public relations and producing their own content. For the past decades, symbolic elements became important inside organisations: brand building and storytelling tools became key elements for economic success. Thus, sports organisations have to put in place marketing and communication strategies to enhance the fan experience to establish a more perennial connection. Following the digital revolution, direct communication between public and organisations became easier and less expensive. Thus, football clubs invested in their own media and communication channels to reach their fans, in order to enhance their connection. In theoretical terms, we want to frame our research inside mediatisation theory, to understand how media logic is implemented into social institutions. Following the perception that communication and media, especially new digital technologies, are important tools, sports organisations change their structure, becoming more complex, and also their behaviour to match their aspirations. Our field work was done at three different football clubs, Benfica, Botafogo and Paris Saint-Germain, where we use an ethnographical-interview approach.to talk to content and media professionals from the club owned media channels. Taking into account the club's viewpoint, we want to discuss the reasons they decided to invest in their own media and communication channels. After our analyses, we identified that football clubs aims to booster the emotional and mediated connection with fans, creating a strong community. Finally, we consider that the media channels owned by the clubs have a phatic function. For the sake of interaction, these channels serve to form and sustain a community of fans.

Keywords: Club owned media, Digitalisation, Fan community, Football clubs, Mediatisation

\section{Introduction}

The Sport/Media complex (Wenner 1989) is changing. Many authors have spoken about this symbiotic or parasitic relationship between media and sport (Helland 2007, Rowe 1996). Media - specially TV - have been an essential tool to the growth of sports industry (Boyle and Haynes 2009). Even after digital revolution, Television remains as the main medium for sports (Hutchins and Rowe 2012), due to its capacity to overcome geographical constraints, and broadcast a match all over the planet, maximizing visibility for a sports team.

For the past years, there are three major causes of change on the sports/media landscape: digitalisation; commodification; and globalisation. By digitalisation we

*Junior Researcher, CPES, Lusófona University, Portugal. 
mean: the growing importance of digital tools on the work, lowering the entry barriers on the media market and transforming the way people work. Commodification enhances the commercial aspects of sports and media supporters become customers as much as readers become clients. Revenues and deals become more present over the sports news. Finally, football is the quintessential global sport, labour, viewers and capital are global, with some leagues, competitions, teams and players attracting millions of followers outside their traditional boarders (Boyle 2006).

In this paper, we want to go beyond the importance of TV or Media for the Sports Industry, analysing the adoption of a "media logic" (Altheide 2004) inside football clubs. One of the first consequences was connected to the relationship with the press. Due to the promotional nature of the sports press (Lowes 1999), and the consequence for the image of the organization, football clubs employ public relations and other press specialists to invest in this relationship (Montañola et al. 2012). Afterwards, clubs put in place communication and media strategies, so, with time, the professionalization of personnel at football clubs reached media and marketing departments. One ramification of this was that clubs became aware the importance of image and visibility and decided to take a part in this instead of leaving everything to media companies (Boyle and Haynes 2004). So they decide to enter the media market.

Our aim is to analyse in what way and for which reasons football clubs decide to adopt media logic. Based on the research of three clubs - Benfica (Portugal), Botafogo (Brazil), and Paris Saint-Germain (France) - we will analyse the role played by club owned channels to understand how the implementation of media practices are introduced to the routines of football clubs, and why these organisations decided to implement these strategies.

\section{Literature Review: Mediatisation of Football Clubs}

Due to the importance of Media to the Sports Industry, Mediatisation (Hjarvard 2008, Hepp 2013) is a significant theoretical framework to study football clubs. Mediatisation is defined "as the influence of media institutions and practices on other fields of social and institutional practice" (Livingstone and Lunt 2014). Mediatisation is about long term structural change on the relationship between media and other social spheres, involving new interactions and social relations, including new patterns of mediated communication. Also, mediatisation depends on the proliferation of the multiple media forms of communication, but what essentially change is the level of access and control over these resources.

Mediatisation is about the interdependency of media, culture and society, being a reciprocal process that affects media as much as other institutions. Furthermore, mediatisation is a process of late modernity, marked by dedifferentiation, specialisation and rationalisation. In this landscape, media plays an important role because it launches institutions into the public sphere where it allows a space of shared experience that enhances the need of differentiation (Hepp 2013). 
Frandsen (2015) researched Danish sports federations to evaluate the effects of mediatisation within sports organisations. She highlighted three components on the analysis: perception; structure and behaviour. First, it is perceived that media is an important factor in society. Second, the organisation changes its structure, investing resources - time, money and personnel - to improve its media capacities. Finally, everything converges in actions and media strategies executed by the sports organisation.

The research results on Danish organisations show that despite the importance of media and communication, there are still many amateurs and volunteers on the job; and the more mediatic and more wealthy, more professional the organisations are. She concludes that mediatisation process is not uniform, and the richest organisations are in more advanced stages (Frandsen 2015). So football clubs and American pro sports are in the forefront of the process, since they have more media personnel, scattered through public relations, marketing, communications and media activities.

Historically, boundaries between Media and Sport are very fluid. Firstly, the limits between the sports and media organisations were crossed by media companies who acted as sports promoters (creating competitions and fostering the game) with economic goals being the Tour de France an emblematic example. Secondly, sports organisations ventured on the media frontier, creating their own media channels, hiring journalists, and other media personnel, to put in place a more complex media strategic plan.

New economic, technological and cultural circumstances reshaped the relationship between football and TV: free to air television was replaced by cable and satellite services as the primary source for viewers. With consumers open to pay extra for sports content, new economic models, based on subscription, were developed (Boyle and Haynes 2004). Also, digital revolution allowed media companies to invest in ways to interact directly with the audiences, and broadcast rights were sliced into packages target for different platforms.

The digital turn was a big step for the commodification process that was in progress. Football broadcast rights were increasing for years, but digitalisation spiked this growth. In England, between 1992 and 1998, prices went up 126\%, in Spain 140\%, and in Germany 168\% (Boyle and Haynes 2004: 55). Based on evidence found about the English market around the turn of the century, Boyle and Haynes (2004) remarked that these positive outcomes were not guaranteed. During early 2000's, the market was pessimist due to the bankruptcy of some media companies after overpriced broadcast rights purchase, such as ITV Digital and Kirch Media. In general, media companies were finding hard to make a profit after paying so high prices.

Afraid to lose some of their revenue, football clubs started investing in their own intellectual property. First, they decide to exercise more control over their image rights (Boyle and Haynes 2004) and branding. Second, they started to explore broadcasting alternatives, in case of rights sales dropped. Digital technologies allowed clubs to explore new ways to monetize their product. Internet and digital TV increase the spectrum of possible audio-visual services at the same time they lower the barriers to entering the media market for content 
producers. Despite elevated production and human resources costs, through digital production, football clubs may integrate vertically their sport, media, and commercial activities. This is possible because new media forms of distribution enable clubs to have more control over their image and brand (Boyle and Haynes 2004).

Manchester United was the first club to launch their TV Channel (MUTV), in 1998, producing content on a daily basis. In an interview on April 2002, the Communication Director spoke about the importance of MUTV for the internationalisation of the club, and maybe, one day, international broadcasting would be done only by MUTV. Peter Kenyon, director of Manchester United, said that the goals of MUTV were: to become more visible; to build relationships and a database; to convert fans into consumers. Other clubs followed Manchester United and created their own channels, despite the different models. MUTV was a pay-tv channel same as Chelsea TV. Arsenal decided for an online-only channel (Boyle and Haynes 2004).

When football clubs create their own TV Channels, they enter the media market. Besides their responsibility to organize sports live events, they also start to explore the sport mediated content, either through match broadcasting or through sports information and content. Uniting match day events and media products, clubs are able to create synergies, increasing their profitability and revenues. However, Television is still the main source of revenue for clubs, and since exclusivity are an important factor for their economic success, most of the broadcast rights continue on traditional media channels (Hutchings and Rowe 2012).

\section{Methodology}

This paper is based on the research of Benfica TV, Botafogo TV and PSG TV. We used an ethnographic-interview methodology (Beaud and Weber 2010), as an attempt of understanding the inner parts of the clubs. An ethnographic approach allows for a better opportunity to gain a deeper understanding of the club, to understand its motivations and how the media production is now part of its universe. The choices of those clubs were due to the originality of their media presence. Benfica was the only club in Portugal to have a TV channel and it broadcasted their live matches. Botafogo was praised by specialized media press as a vibrant and creative marketing department. Different than their football rivals, Olympique de Lyon and Marseille, PSG chose to launch a WebTV instead of a pay-tv channel.

At Benfica, a week-long observation period was followed by interviews with seven journalists among the 18 who work at Benfica TV. The period of observation was determined by the Benfica TV direction, but the length of research was defined to cover all aspects of the broadcast, including one Benfica match. At Botafogo and PSG, a period of observation was not allowed, due to the size of the media department, and the negative implications that an outsider presence could bring to the work environment. In order to minimize the lack of 
observation, we performed the interviews at their workplace. At Botafogo we spoke with 5 people of a total of 7 staff team. At PSG, we talked to 4 professionals among 6 who work there. The interviews were conducted between December 2013 and July 2014. Also, to enrich the study, the research was complemented with a document analysis such as annual reports and information published in the media - the size of the clubs and its number of supporters is the reason why it appears so often in the news pages, not only figuring in the sports content, but also in the political and business contents.

\section{Findings: Club Owned Media}

Football clubs are a very diverse type of organisations. From its Victorian origin, with the global reach of the sports, in each country they might have their own set of rules and they also vary in size, history and business models. The three clubs chosen presents a different model: Benfica is an anonymous society, Botafogo is a not-for-profit organisation with members taking the decisions and Paris Saint-Germain is a limited company owned by a billionaire.

Despite their differences, their approach to communication presents a similar path. As consequence of commodification, clubs went through a rationalisation process, where the non-athletic staff became more professional and specialized (Gasparini 2000). Due to its commercial relevance, football was the starting point for the changes. Marketing departments were created in order to deal with sponsors, and also, a public relations and communications section should deal with the media.

Sports organisations sponsor and the media are responsible to create the sports spectacle. In this scenario, it is understandable that clubs prioritize their relationship with the media and the sponsors. For the media, football is a great content, being able to attract large audiences. For sponsors, football clubs are a very good advertisement platform, due to its visibility and emotional bond with supporters.

The main concern related to the media is to harness "good press". Despite their ethical and deontological procedures, sports press has a promotional outcome for football clubs (Lowes 1999). So, it is in the interest of clubs to create a good environment for journalists. On one hand, they offer services to facilitate their work routines, with press rooms, food, Wi-Fi and other facilities. On the other hand, clubs try to control the information with press releases and press conferences, minimizing the contact between journalists and athletes.

Part of this control was a consequence of digital revolution. Digitalisation lowered the barriers to enter into the media market, allowing for the multiplication of media outlets and increasing the number journalists covering sports. So clubs had to organise, rationalize and control the access to their facilities and athletes. Also, digitalisation allowed clubs to invest on their own media platforms to communicate directly with the press and the fans.

Among the researched clubs, PSG was the first to create their own TV, in 2007, followed by Benfica in 2008 and Botafogo that have been experimenting 
since 2012. PSG.TV is a freemium web-tv channel, where part is free and part is behind a paywall. Benfica TV (or BTV) is a pay-tv channel available for a subscription fee. Botafogo TV is the name given by the club to the use of social media and open platforms, such as Youtube, Facebook, Instagram and Twitter to post videos produced by the club. Based on the interviews, Botafogo TV and PSG.TV had no profitability obligations to reach, while Benfica TV had an important role in Benfica's finances.

Broadcast rights contracts renegotiation are landmarks for the implementation of club owned media. The ability to explore their own image and intellectual property decided by these contracts is essential to produce contents. Ligue 1 (The French Football League) has a collective agreement, and after 2007, French clubs were allowed to use games highlights, to broadcast games where Ligue 1 was not offered, and to make available past games on demand.

When Benfica TV was created, they had the rights to broadcast only their amateur and semi-pro sports, such as basketball, hockey, volley and others. But in 2013, after a failed attempt to renew the broadcast deal, Benfica decided to broadcast their home matches on its own TV channel, changing their business model from an open pay-tv channel to a premium pay-tv with a 9.90-euro subscription. Portuguese clubs negotiate individually their broadcast rights, owning all their home matches. So, since 2013/14 season Benfica TV is in charge of broadcasting all Benfica's football encounters at Estádio da Luz. They broadcast live games and reprise some matches.

In Brazil, the collective negotiation was replaced by individual agreements. However, this change was unable to provoke actual modifications. TV Globo conglomerate remains the rights holder for every national football competition in their free to air stations and their pay-tv services. Brazilian football clubs have a very fragile financial situation, and they are highly dependent of TV Globo, because the company usually pay in advance the broadcast contract's fee. This unbalanced power, leaves Botafogo in a situation where the club is unable to explore game highlights or broadcast images. Furthermore, Globo pay-tv services agreed with first division Brazilian clubs to produce, in partnership with them, a 30-minute television show about the clubs. In Botafogo's case, they called this program "Botafogo TV".

Constrained by the lack of access to their highlights and games of senior football squad, Botafogo content must adjust to their reality. In this sense, they explore their access and produce behind the scenes videos, with players arriving at the stadium, the locker room talk before or after the games, but this type of content is highly conditioned by results obtained, meaning that in case of defeat there is fewer offers. Also they offer videos and information about youth football and other sports played by the club.

As an online channel, PSG.TV offer videos (an average of 100 per week, in French, English and Spanish) and live streaming. Matches and 10-minute highlights are behind a pay-wall and the other content is free. There are some regular videos - such as match highlights, daily news and a weekly "This is Paris" 
show - and some more diverse offer. In general, video content ${ }^{1}$ tends to approach sport through an entertainment lens, putting players in game-type situations, exploring their intimacy and personal tastes, aiming to appeal for young audiences. Usually, PSG live streams some training sessions and press conferences.

Benfica TV programming is structure like traditional television. As a pay-tv channel, they broadcast 24/7, where live events and news are the main content. The most important event is the football match, but they also broadcast hockey, basketball, volleyball, handball and youth football. There are four live daily news (at 10h, 14h, 21h and 24h), documentary and debate shows. BTV cover everything related to the club, not only sports but also the club's social events and fan's associations activities. Their goal is to value the Benfica's image and memory, connecting with fans to reinforce their bond around the club.

Based on our interviews, to be the official media of the club is a very important aspect of the work. To produce content with the organisation's brand means that staff have extra pressure to not make mistakes, because they act as the voice of the club. The zero-margin for errors is the reason why one of Botafogo's media professionals said that he had more responsibility working for the club in comparison with his previous job at a sports newspaper. To be the official channel is the source of credibility for club owned media in contrast with ethical guidelines of traditional press.

As seen in the three organisations, match content and highlights are very relevant for club owned media. Despite the different business models, each club share the same element to create value: senior football squad images. The majority of audience want to see goals, highlights and nice moments, but exclusivity is a key component of broadcast rights fees. Clubs are able to control their training grounds and stadiums - allowing for behind the scenes content - but Television are able to commercialise and target bigger audience than club owned media, so they can pay more than clubs are able to profit.

Club owned media allow clubs to build synergies and verticalize the production in order to maximise profits. With media participation, clubs are able to take part in most of the sports spectacle chain of production, from youth academies to managing the stadium, the sale of merchandise products and content production, covering the team. Club owned media are able to create synergies between the club's departments and to cross-promote club's activities and add value to their most important asset, the match day experience (at the stadium or on TV), increasing ticket sales and marketing opportunities.

For sponsors, club owned media are an extra platform to advertise. Benfica TV has a specific show, where corporate sponsors are invited to showcase their business and talk about their relationship with the club. PSG uses their videos to promote sponsor's activities inside the stadium on matchday. Botafogo creates photo albums and videos highlighting sponsors in the background images. Also, for the three clubs, football sponsors are the main advertisers of their channels.

Like the importance of Television shows, images are very important for sports media. However, club's media activities are not limited to their TV channels.

${ }^{1}$ PSG TV: https://www.psg.fr/psg-tv 
Benfica also publish a weekly newspaper and a monthly magazine. PSG.TV team are also in charge to produce magazines and stadium's big screen content. Botafogo also produces for big screens, a matchday magazine and a web radio. Also, the three clubs invest highly on their websites with news and official content.

Clubs are not limited to a variety of media platforms, they also have shown a specialisation in relation to media and communication services. Benfica and Paris Saint-Germain had special teams to work separately with Customer Relationship Management, Social Media, Public Relations and club museums. At Botafogo, the communication team is partially responsible for most of this work, the staff does a little bit of everything, from writing, editing, doing internal and external communications for the club and hosting guests at the visit tour, with the expectation of senior football public relations that is outsourced to a private company. Our research was focused on the content production of club owned media, therefore for both European clubs who have a more specialized division of work, we were unable to access these other sections.

This situation shows that mediatisation and professionalization process of football clubs have different speeds for the clubs. The superior amount of specialized work at Benfica and PSG confirms that they are more developed in management terms then Botafogo. In parallel, this also means that, in Europe, football is more globalised and commodified, thus influencing their relationship with fans and in regards to their communication and media strategies.

The different speed of mediatisation is also reflected on the staff profile and recruitment. Botafogo staffs were hired based on personal connections and senior editors had previous experience as beat reporter of Botafogo football team. Most of Benfica media professionals were young and with little experience in other fields of media work, but after BTV became a premium channel; they hired 4 national well-known journalists to do the broadcasting and to lead the journalistic team. At PSG, every member of the staff speaks more than one language and they all had previous work experience in similar jobs before. Botafogo and PSG had all-male staff, while around one third of content production staff at BTV was composed of women.

With the exception of PSG.TV, all the staff members were also supporters of the club. PSG hiring process seemed to be based more on qualifications and experience skills, thus limiting the talent pool. However, two of the professionals interviewed, said that despite their initial fandom for other clubs, the empathy for PSG grew with time. In general, what we saw was a bond between employee and employer that went beyond usual professionalism. The research showed a group of professionals who were passionate about their jobs, and who saw themselves as part of something bigger. Also, they understood that their work was partially responsible for the success of the club, giving them a double satisfaction: as fans and as workers.

Their affinity and knowledge of the club plays a key role in content production. At Benfica and Botafogo, they understood that it is not possible to work for a club owned media without being supporter of the club. The interviewees saw themselves as part of the audience, because they related with them as fans. In their view, this gives an advantage to get into the psyche of the public to know 
what they want and what they feel, thus offering content appropriated to each time of the season.

As virtual means of internationalisation, club owned media might have a strategic role to play. Since Botafogo most important international commodity is the player, the club's efforts focused on youth team tours. Benfica TV is available in nine countries (France, Luxemburg, England, Switzerland, Cape Verde, Angola, Mozambique, USA and Canada) and their partial content is broadcast in partnership with local companies in Belgium and Brazil, in addition to the service of live streaming in dozens of countries spread through all continents. The international strategy is a key aspect for the life of the club because a survey in 2005 showed that there were 14 million Benfica fans in the world, 5 million in Portugal, 500,000 in the rest of Europe and 8.5 million across the rest of the world (Pereira 2013). PSG.TV has an important role in the international strategy for the club. Their website is available in 7 languages (French, English, Portuguese, Spanish, Chinese, Arabic and Indonesian), the play-by-play are available in French, English, and Spanish, as some of the videos. Also, PSG increased their international presence through preseason and mid-season tours, which are highly mediated by the traditional press and by PSG.TV. As a brand, PSG builds its brand in association with the international perception of Paris. Being PSG's hometown, the club wants to borrow the elegant identity to their football team.

\section{Discussion: Connecting with Fans}

The recognition as an economic activity justifies the use of Marketing strategies on sports management. Thus, sports organisations put in place new work routines, based on rational and professional procedures, in order to better build the sport spectacle and to connect with their fan base. Taking into consideration the width of Marketing activities, we will focus here on the ones related to Media and Communications.

Due to the connection that Marketing has with client, first of all, we must ponder about the notion of fan base. Football supporters may have different patterns of behaviour and a varied level of identification with a club (Sandvoss 2003, Giulianoti 2002). With the commodification of the game, clubs tend to see then more based on their consumer status (Horne 2006) than their traditional identity. Regardless of this duality, fans must also be seen as television audiences (Rowe 2011), due to the reach of satellite broadcast and the global presence of certain football clubs.

More than compete for the supporter affection, nowadays football clubs must battle for attention. In a busy entertainment market, including different sports options and other type of leisure activities, football clubs must find a way to retain the relation with their fans and consumers. For a die-hard supporter, this connection is not in jeopardy, so organisations invest their resources to attract fans who are in the middle of the spectrum of affection, between the die-hards and those who are disinterested (Rein et al. 2008). 
In order to foster this relationship with fans it is vital to build upon the identity and brand of the club. In Marketing, brand equity indicates the brand's value, based on the idea that well-known brands generate more revenue than unknown. In football, brand equity is in the center of the relationship between fans, sponsors and the media: the success of the club means the fans are more satisfied, the media will provide more visibility and the sponsor will profit from the exposure. Also, well-known brands are able to recruit better players and coaches (Guenzi 2007).

As an agonistic activity, there are certain elements that escape the control of the organisation. Victories, defeats, championships play an important role in the capacity to attract fans and revenues for the club, but sometimes they are out of the reach of the club. For sports brands, it is essential to build its brand regardless of the results in the field. Despite its importance for a football team, a club must offer a product independent of victories, allowing every club - on top or at the bottom of the standings - to elaborate a marketing plan. This does not mean that performance is not a key aspect to build a brand, as we see FC Barcelona style as one very important characteristic of its brand.

Athletes, federations and other actors also develop their brands, inside the football industry. Brands may offer a long term message and those clubs that link this with a remarkable experience are able to create a very strong bond with fans (Rein et al. 2008). However, to present a perennial character, a sports brand must remain loyal to its principles and authenticity, because otherwise it may be diluted, opening opportunities to the competition (Desbordes and Richelieu 2011).

Branding has become an important tool for sports organisations. Therefore, for the past years, football clubs have implemented specific strategies to reinforce connection with fans, transforming it in a competitive edge. The importance of this emotional link underlines the need to invest on symbolic elements of sports to link people and institutions. In this sense, the creation of emotions, memories and a vibrant atmosphere is crucial.

As part of the entertainment industry, football is a good example of the Experience Economy (Pine and Gilmour 1998). For the past decades, symbolic elements became important inside organisations: brand building and storytelling tools became key elements for economic success. Thus, sports organisations have to put in place marketing and communication strategies to enhance the fan experience (Desbordes and Richelieu 2011) to establish a more perennial connection. The emphasis on the experience, on brand building and storytelling are strategies of dedifferentiation.

The acceptance of club owned media is related to the changes in journalism and sports media landscape (Boyle 2006, Hutchings and Rowe 2012). As a result of the crisis of traditional media outlets, football clubs occupy a place in the media market to offer exclusive and official information about themselves, communicating directly with the audience. In order to do so, football clubs start to change its structure to echo media companies and to behave according to the media logic.

At the present, it is no longer possible to stay out of the Media. The importance of broadcasting for global markets forces football clubs to have any kind of plan concerning their media presence (Hutchings and Rowe 2012). As late 
modernity advances, and also in competitive markets, the need to differentiate grows. Thus, organisations will push different types of mediatisation to achieve its own objectives. For all the many possibilities of big and small clubs, more corporate or more traditional, one thing is certain: there is no success in sports today without a strong presence on the media landscape. Either as revolutionary or more conservative, every sports organisation need a communication strategy and need to be media active.

In general, the power of the media is related to the attention it generates. Hjarvard (2008) states that mediatisation is about the growing influence of public attention in other fields and institutional spaces. Media are social tools to produce attention, but its real asset is the capacity to control how information is represented (either framed or narrated); how relationships are built; and what are goals/effect of any communication process (entertain, inform or persuade).

What we see is the reflection of what Frandsen (2015) stated. Football clubs perceived that media and communications is an important aspect for them, in order to foster relationship with fans, with sponsors, with the media, and to build their brands. So they structure themselves with Communications and Marketing departments, Public Relations staff or even their own TV or Web based channels. In doing so, they start to behave a little bit like a media company and not only as a sport organisation.

Benfica, Botafogo and PSG reinforce this view. Their perception of the importance of media, especially new media, for sports push them into the media landscape. They use their channels to connect directly with their fan base, to provide extra advertisement space for sponsors, and to control and manage the narrative around the club.

Furthermore, these three clubs demonstrate the different speeds in the process of mediatisation. Each one has chosen a different business model suitable to their goals, structure and resources available. Benfica's dominance in Portugal allows the club to profit from a subscription based model, replacing traditional media. Botafogo's poor financial situation and media dependency compels the use of social media platforms and the absence of match highlights. Whereas PSG international squad, including world class talent, provides the room to an international strategy.

Club owned media are strategic tools for a solid marketing and communication plan. First, investing in its own channel is important to manage the content consumption. Sports texts are read in three phases: before, during and after the matches. Media have a key role before and after (with news, game analyses, interviews, etc.) and an accessory role during the game (second screen or $\mathrm{Wi}-\mathrm{Fi}$ at the stadiums). In general, this type of consumption aggregate value to the live event and it will boost the emotional and mediated connection with fans. Second, club owned media increase the perennial connection with fans, and it is an important factor to build a strong community around your club and brand.

This strategic role is outlined by the lack of profit requirements presented by Botafogo and PSG. The results aimed by the media department are aligned with the overall goals of the institution. Their media channels aim: to increase matchday attendance and season ticket sales; to internationalize the club's brand, 
expanding their market and fan base; to grow the visibility of the brand, and through narratives transform this contact into empathy for the club; and to promote club merchandising. Despite Benfica TV's commercial obligations, before the club decided to broadcast their matches, they had the same strategies. BTV profit requirement comes from the need to replace the rights sale for their own production.

Club owned media have a phatic function. These channels serve to form and sustain a community of fans spread over a country or the globe. They identify with a specific club, but this relationship must be nurtured virtually, based on mediated interactions. The media allows for a delocalisation of traditions, where mediated relations replace direct contact, and transform time and space. Thus, local clubs may contact and form a global community with fans who never share the same space, and interact only using media and virtual means.

Based on a content production on demand, it is possible to see a phatic type of journalism. The phatic function concerns the contact between the sender and the receiver, in which certain messages aim to establish, maintain or interrupt the communication between them. The priority is to guarantee the continuity of the connection between every member of the community. Sometimes the relationship with the audience precedes the quality of the messages (Estienne 2007).

The exacerbation of this function is a one of the distinctive traits of a Communication Journalism. According to Brin, Charron and Bonville (2004), the objectives of this type of journalism - to generate attention, to establish and to maintain contact - reinforce the phatic function. In order to reach these goals, every elements of discourse are used to create an illusion of interpersonal communication with the public. The content produced essays to pose as a conversation, and to build an inter-subjectivity relationship.

The same phatic function is seen at club owned media. Relying on the sports aptitude to connect people, the media texts use this power to unite the audience around one entity. It is not just matter of technology or communication techniques, but also ideology. Sports texts have the power to unite audiences into coherent groups, either for a long or short period of time (Rowe 2003). This phatic function can be seen regarding the concern with the public, composed by supporters of the club. It is clear that supporters are already a cohesive group, but the information and content produced serve as a way to unite more people around the club. Club owned media content serves to strengthen the emotional bond, ensuring that the fans remain faithful and invest their time in this club.

This concern with the consumer justifies the recruitment of professionals who are also supporters of the club. In spite of internal variation, as members of the same group, they have a keen understanding of the public's desires. At the same time, it strengthens the sense of community between readers and content producers; hence both sides have the sense of belonging to the same club. 


\section{Conclusions}

More than match promoters and organizers, sports organisations have become content producer after the creation of club owned media. Thus, they become able to apply more control over the symbolic elements and the narrative around the facts, in order to increase club's visibility and promotion. This ability to shape discourse is essential to build a solid and perennial brand, because it helps to consolidate the club's values and identity.

The entrance of clubs into the media landscape allows them to cover more parts on the chain of production of the sport spectacle. The management of symbolic material reinforce the experiential aspect of the football business, making the manufacture of a good atmosphere and memories associated to the games a priority for clubs. Moreover, club owned media content allow for cross promotion and the enlargement of the contact interval with their fan base.

Through content and other synergies actions, football clubs are able to connect with more people, during a longer period of time. As an official channel, the relationship formed is a direct bond with the club. For scattered audiences, who no longer have a local and direct contact with the club and players, this mediated interaction is a valid substitute in a late modern time. Furthermore, as a media product, a football match is free of any geographical constraints, being available to global audiences.

The content created has a phatic function to maintain the constant contact with fans. 24/7 pay-tv channels or on demand online platforms are available for fans anytime, anywhere in almost any device, giving the possibility of a full time connection between fans and club. The sense of community is reinforced by content that shows intimate moments of players, through their personal lives or sharing behind the scenes images.

The ties among the members of this virtual community are strengthened by the staff profile. Since, the great majority of content producers are also supporters of the club they have a lot in common with the audiences, understanding their moods, sharing feelings, and memories. Likewise, both content producers and audiences have the notion that their work or subscription (paid or not) contribute, directly or indirectly, to the success of the club in the field.

By investing in the production of sports content, football clubs try to engage with fans all the time. There are no professional sports without media and no sports at all without engagement to fans. Regardless of the medium or technology, clubs must connect with fans. The analysis of the content produced (nostalgia videos and past glorious matches, intimate moments for players and staff, dressing rooms and training grounds, youth team matches) may offer a view that the strategy includes past, present and future connection. 


\section{References}

Altheide D (2004) Media logic and political communication. Political Communication 21 (3): 293-296. DOI=10.1080/10584600490481307.

Beaud S, Weber F (2010) Guide de l'enquête de terrain [Guide to the field survey]. Paris: La Découverte.

Boyle R (2006) Sports Journalism: Context and Issues. London: Sage.

Boyle R, Haynes R (2004) Football in the new media age. London: Routledge.

Boyle R, Haynes R (2009) Power Play: Sport, The Media and Popular Culture. Edinburg: Edinburg University Press.

Brin C, Charron J, de Bonville J (2004) Nature et transformation du journalisme. Théorie et recherches empiriques [Nature and transformation of journalism. Theory and empirical research]. Québec: Presses de l'Université Laval.

Desbordes M, Richelieu A (2011) Néo-marketing du sport [Neo-marketing of sport]. Bruxelles: Editions De Boeck

Estienne Y (2007) Le journalisme après Internet [Journalism after the Internet]. Paris: L'Hartman.

Frandsen K (2015) Sports Organizations in a New Wave of Mediatization. Communication \& Sport 4(4): 385-400.

Gasparini W (2000) Sociologie de l'organisation sportive [Sociology of sport organization]. Paris: La Découverte.

Giulianotti R (2002) Supporters, Followers, Fans, and Flaneurs: A taxonomy of Spectator Identities in Football. Journal of Sport and Social Issues 26: 25-46.

Guenzi P (2007) Sport marketing and facility management: from stadiums to customerbased multipupose leisure centre. In M. Desbordes (dir.), Marketing and Football: an international perspective. Elsevier: Oxford, 130-162.

Helland K (2007) Changing Sports, Changing Media: Mass Appeal, the Sports/Media Complex and TV Sports Rights. Nordicom-Information 29(2): 105-119.

Hepp A (2013) Cultures of mediatization. John Wiley \& Sons.

Hjarvard S (2008) The mediatization of society: A theory of the media as agents of social and cultural change. Nordicom Review 29(2): 105-134.

Horne J (2006) Sport in Consumer Culture. Basingstoke: Palgrave.

Hutchins B, Rowe D (2012) Sport beyond television: the internet, digital media and the rise of networked media sport. London: Routledge.

Livingstone S, Lunt P (2014) Mediatization: an emerging paradigm for media and communication studies In Lundby, K. (Ed.) Mediatization of communication (Vol. 21). Berlin: Mouton de Gruyter, 703-724.

Lowes M (1999) Inside the Sport Pages: work routines, professional ideologies, and the manufacture of the sports news. Toronto: University of Toronto Press.

Montañola S, Romeyer H, Souanef K (2012) Journalistes et communicants: cohabitation «forcée» et co-construction de l'information sportive [Journalists and communicators: "forced" cohabitation and co-construction of sports information]. Les Enjeux de l'Information et de la Communication 13(1): 143-157.

Pereira L (2013) Luís Felipe Vieira-Missão Benfica [Luís Felipe Vieira - Benfica Mission]. Lisbon: Prime Books.

Pine BJ, Gilmore JH (1998) Welcome to the experience economy. Harvard Business Review 76(4): 97-105.

Rein I, Kotler P, Shields B (2008) Marketing Esportivo: a reinvenção do esporte na busca de torcedores [Sports Marketing: the reinvention of sports in search of fans]. Porto Alegre: Bookman. 
Rowe D (1996) The global love-match: Sport and Television. Media, Culture \& Society, 18(4): 565-82.

Rowe D (2003) Sport, Culture and the Media: The Unruly Trinity. Buckingham: Open University.

Rowe D (2011) Sport and its Audiences. In V. Nightingale (dir.), The Handbook of Media Audiences. Oxford: Wiley-Blackwell, 509-527.

Sandvoss C (2003) A game of two halves: football, television, and globalization. New York: Routledge.

Wenner L (1989) Media, sports, and society: The research agenda. In L. Wenner (ed.) Media, Sports and Society. Newbury Park, Calif.: Sage Publications, 13-48. 
